\title{
COGNIÇÃO E ORALIDADE DA CULTURA CAIPIRA: EFABULAÇÃO E EPISTEMOLOGIA EMPÍRICA.
}

Daniel Batista Lima Borges ${ }^{1}$

\begin{abstract}
RESUMO
O presente artigo visa à construção de uma perspectiva de análise de narrativas orais considerando os aspectos cognitivos relacionados ao ato de efabulação oral. Nesse sentido, faz-se necessário o delineamento de bases psíquicas envolvidas no trabalho com a palavra feito por indivíduos da cultura caipira do município de Caçapava-SP. Para tanto, propõe-se, como ponto de partida, a relativização de alguns pressupostos de Os parceiros do Rio bonito, de Antonio Candido, no sentido de se considerar as especificidades simbólicas da oralidade caipira como forma de resistência e atualização em relação às mudanças econômicas que atingem o Vale do Paraíba. Nesse contexto, a análise literária permite delinear as mediações formais que a palavra assume ao expressar a experiência individual e a relação do indivíduo com seu contexto sociocultural.
\end{abstract}

Palavras-chave: Teoria literária. Oralidade. Cultura caipira. Cognição. Epistemologia.

\section{INTRODUÇÃO}

Visando ao estabelecimento de parâmetros metodológicos para a pesquisa da oralidade caipira no Vale do Paraíba, verificamos a necessidade da exploração de perspectivas sobre a cultura caipira, de modo a encontrar um ponto comum que consiga apreender nexos sociais atuais sem desvalorizar a complexidade dos indivíduos que compartilham os símbolos dessa cultura².

De acordo com (THOMPSON, 2002, p. 325), a oralidade constitui fonte legítima e insubstituível a recuperar informações que não se encontram em artigos e livros, mas que traz também, inerentemente, a marca da subjetividade. Assim, nos propomos a trabalhar no âmbito do microssocial, colocando em primeiro plano o 
relato individual.

Nosso corpus de análise são as narrativas de um contador de causos e de outras formas simples: André Emboaba (2013). De uma recolha oral de aproximadamente 20 horas com o mesmo narrador, pudemos extrair pequenos trechos que nos possibilitarão discutir alguns aspectos da relação entre cognição e oralidade na cultura caipira.

Levando em conta que nossa pesquisa parte da Teoria Literária como método de analise oral, e trata de narrativas caipiras, é praticamente impossível passar ao largo dos estudos de Antonio Candido. Em seu grande estudo etnológico, Os parceiros do Rio Bonito, encontramos a habilidade intuitiva do crítico literário, que permite uma pesquisa participante guiada pela sensibilidade, formando um método de pesquisa etnológica que visa atender às especificidades do grupo de caipiras estudados. Isso faz com que o autor faça um percurso que vai do micro ao macroestrutural, colocando a comunidade, com suas expectativas mais elementares, em primeiro plano dentro de um quadro sociopolítico nacional.

No entanto, alguns pressupostos de Os parceiros acabam por simplificar os processos psíquicos em benefício da análise sociológica que une o materialismo histórico ao funcionalismo. O caipira sofreria de uma obsessão pela comida que definiria sua materialidade e produziria "representações míticas e religiosas insuficientemente formuladas." (CANDIDO, 2010, p. 31). Por um lado, isso permite apreender as dinâmicas sociais das comunidades como um todo, e sua inserção no sistema global capitalista. Mas, muitas vezes, tende a tolher a liberdade de escolha do indivíduo em relação às mudanças. Assim, o caipira acaba sendo visto como uma vítima do consumismo capitalista.

Desta forma, em primeiro lugar, faz-se necessária uma atualização de algumas ideias de Os parceiros do Rio Bonito, no sentido de se considerar possibilidades de resistência em relação às mudanças socioeconômicas por que passam as comunidades rurais. Somente assim poderemos discutir aspectos cognitivos relacionados à oralidade caipira.

Isso porque acreditamos que há resistência simbólica a imposições advindas de mudanças conjunturais, e que pode ser verificada na produção oral de diversos narradores. A particularidade mais marcante desta produção oral é a de formar um equilíbrio cultural que não é facilmente detectado por dados estatísticos ou aparatos de poder, pois permanece à margem dos mecanismos institucionais. 
Em nossa perspectiva, acreditamos que muitos diagnósticos apocalípticos sobre a cultura caipira não levam em conta a maneira como é feito o consumo do que é aparentemente imposto pelo capitalismo consumista. Assim, esta oralidade passa ao largo de estatísticas, pois, o que seria o final do processo, para nós significa apenas o início do que se pode chamar de liberdade cotidiana em que o indivíduo escolhe as imagens que quer ressignificar. A maneira com que esta liberdade é exercida aponta para a multiplicidade que compõe o sujeito, e nos permite avaliar como a oralidade escapa às determinações econômico-sociais.

Para que se possa analisar esta oralidade, faz-se necessário o delineamento da complexidade cognitiva que permite, ao mesmo tempo, a não submissão às determinações, e a criação simbólica, que articula e compartilha os símbolos da cultura. Isto implica o estudo de dois aspectos da cognição:

a) $O$ desenvolvimento cognitivo implicado no ato de efabulação, o que significa o delineamento do universo pulsional que move na direção da ressignificação da experiência individual, e a consideração do conhecimento gerado na narração oral em seu caráter espontâneo e que produz sempre algo novo. Isso nos permitirá verificar se realmente a fixação pela comida, conforme determina Candido (2010, p. 59) compromete a cultura.

b) tendo em vista que, muitas vezes, o indivíduo das zonas rurais é tipificado como sendo incapaz para a abstração, e determinadamente fadado apenas ao conhecimento empírico, nos propomos a verificar algumas bases deste pensamento. Para tanto, a análise epistemológica do que se pensa ser o conhecimento empírico pode ajudar na desmistificação de concepções idealizadas sobre a possível simbiose do caipira ao meio natural, que determinariam sua precariedade e rusticidade e o impediria de se desenvolver.

\section{OS PARCEIROS DO RIO BONITO: O CAIPIRA E A NECESSIDADE DA REFORMA AGRÁRIA}

Até meados do século $X X$, no Brasil, ainda não havia nenhum estudo rigoroso da cultura caipira, nem na história, nem nos estudos de cultura em geral. Assim como não havia a sistematização de um método que considerasse sua existência concreta dentro das questões sociais mais abrangentes pelas quais se pensava a sociedade brasileira. Assim, Antonio Candido, em Os parceiros do Rio bonito, foi um 
dos primeiros a pesquisar com proximidade e metodicamente a cultura das populações rurais do Brasil.

Publicado em 1956, uma das preocupações do livro são as transformações sociais em relação à urbanização. O caipira, segundo o recorte proposto, daria a medida destas transformações, pois se configuraria entre o sitiante autônomo e o trabalhador assalariado, sendo que o estudo de suas expectativas ofereceria dados para compreensão da assimilação da cultura caipira pela sociedade abrangente.

O livro, entretanto, supera essa questão e apresenta uma síntese analítica da formação da sociedade caipira, que se relaciona diretamente à colonização no estado de São Paulo, voltada para a penetração do interior, ao contrário de outras regiões do Brasil. Dessa forma, o teórico insere o grupo estudado em uma interpretação ampla da sociedade, a partir das especificidades de sua formação histórica. Ao analisar o caipira a partir de sua historicidade, o autor chama a atenção do leitor para os grupos marginalizados da colonização, não apreciados pelas grandes interpretações de nossa formação até então.

De maneira simplificada, podemos dizer que, visando descrever os traços caipiras do grupo estudado, Candido faz a comparação entre os caipiras e a sociedade abrangente. Para tanto, lança mão das noções de "mínimo vital" e "mínimo social" como parâmetros, pois permitem comparar grupos sociais em "situação de mudança" a sociedades "civilizadas".

Para a cunhagem dessas noções, Candido reconstrói as condições de vida do caipira antes do impacto da urbanização, que se intensifica no final do século XIX. O caipira é definido como sendo resultado do "ajustamento do colonizador português ao Novo Mundo, seja por transferência e modificação dos traços da cultura original, seja em virtude do contato com o aborígene." (CANDIDO, 2010, p. 25). De acordo com essa perspectiva, o caipira seria um produto da colonização, regredindo culturalmente devido ao isolamento a que teria sido submetida a região de São Paulo desde o século XVI. Esse contexto teria produzido uma cultura que, na melhor das hipóteses, teria, como principal característica, uma rusticidade advinda da precariedade mais elementar.

Em decorrência dessa reconstrução, a relação entre a aquisição dos meios de vida e as formas de sociabilidade correspondentes estabelece o tema principal do estudo. O grupo de caipiras é estudado a partir das afinidades que estabelece com a natureza para sobreviver, (o que os aproxima do indígena), e tendo a satisfação das 
necessidades como mola da cultura.

Nesse sentido, considerando que a alimentação seria a principal necessidade humana, impreterível em qualquer grupo e circunstância, dessa relação entre produção dos meios de vida e sociabilidade destaca-se a produção da dieta como definidora de todas as dimensões da vida social. Com base nesses pressupostos, o autor propõe, como método, uma "sociologia dos meios de subsistência", o que the permite uma abrangência teórica imensa, pois consegue relacionar um grupo até então esquecido ao paradigma civilizatório da cultura ocidental. A importância do método, baseado no estudo da precariedade material, está na sua capacidade de dissolver qualquer trabalho apologético de análise, como os estudos de Cornélio Pires, marcados pela simpatia muitas vezes exacerbada pelo caipira; ou ainda, investidas preconceituosamente classistas como as de Monteiro Lobato ${ }^{3}$.

O estudo permite também descrever o choque desintegrador que o caipira enfrenta ao se deparar com a urbanização e a industrialização das zonas rurais, problema que encontrava o ápice de sua tensão quando da década em que o livro foi publicado, 1960. É nesse momento que Candido denuncia o caráter destruidor do progresso em relação à organicidade comunitária e pobre de expectativas materiais da cultura caipira. De acordo com o autor, essa cultura

[...] não foi feita para o progresso; a sua mudança é o seu fim, porque está baseada em tipos tão precários de ajustamento ecológico e social que a alteração destes provoca derrocada das formas de cultura por eles condicionada. (CANDIDO, 2010, p. 82-83).

Isso porque, segundo o autor, uma vez que o caipira se depara com novas expectativas, advindas da sociedade de consumo, a continuidade da tradição é radicalmente desfeita e o universo social e natural do caipira fragmenta-se. Considerando que antes o caipira vivia em uma totalidade comunitária, com a mudança, várias dimensões sociais (a religiosidade, o trabalho, e o lazer) ganham autonomia e não mais se interpenetram. Assim, as transformações levam o "meio total", caracterizado pela indiferenciação social, a uma reorganização no sentido da incorporação à sociedade de classes ${ }^{4}$.

Diante desse quadro de mudanças, Candido atribui à falta de vontade política de integrar o homem rústico, como sendo a origem da condição precária, senão miserável, a que se reduz o caipira em meio ao processo de incorporação à vida urbana. Isso justifica uma proposta política baseada na inclusão e não na exclusão 
das populações rústicas inseridas no processo de urbanização inevitável, visando melhorar seu nível de vida. Note-se que, ainda na roça, a exploração exercida pelos grandes fazendeiros sobre os parceiros, tendo origem na expulsão dos caipiras pelo monopólio da terra, é devidamente apontada pelo autor como formadora das relações de exploração do homem do campo.

Entretanto, a crise não afeta apenas o homem do campo, mas também a todos aqueles que questionam o avanço desenfreado da industrialização e da proliferação de modelos de consumo incompatíveis com a desigualdade social brasileira ou mesmo mundial. Em vista disso, o autor indica uma proposta política que abrange não somente as comunidades rurais do Estado de São Paulo, mas de todo o Brasil: a reforma agrária, norteada por estudos sobre a cultura e sobre a sociabilidade das populações rurais, uma vez que o latifúndio não se justifica de maneira alguma.

Levando em conta este brevíssimo resumo de uma obra tão vasta e importante, fazem-se necessárias algumas considerações em relação à formação de nossa perspectiva.

Os Parceiros do Rio Bonito descreve um momento social: a crise inevitável causada pela insuficiência do sistema agropastoril na região oeste do estado, o que fazia diminuir a oferta de trabalho no campo. A época de Os parceiros impunha a necessidade de se pensar a reforma agrária como sendo mais que urgente, e, certamente, se houve algum avanço quanto à execução desta necessidade de primeira ordem no Brasil, certamente foi em decorrência de pessoas que lutaram no campo para que suas vozes fossem ouvidas, e de pensadores que estruturaram suas condições de possibilidade, como Antonio Candido.

No Vale do Paraíba atual, mais precisamente no município de Caçapava ${ }^{5}$ SP, a crise, relatada por Candido, pela qual passava os parceiros de Bofete, (região Oeste do estado de São Paulo), na década de 1950, que solaparia as comunidades rurais, já atingiu seu ápice, na década de 1980. Os bairros foram, em sua maioria, dissolvidos e sua população engordou as periferias, oferecendo seus braços às fábricas desde a década de 1960, quando o Vale entrou na agenda econômica nacional como polo do desenvolvimento industrial.

Há uma distância de mais de cinquenta anos desde que o livro de Candido foi escrito, sendo que era impossível prever o destino das comunidades rurais do interior de São Paulo diante da conjuntura da época, fazia-se necessário assumir 
determinadas posições políticas fundamentais diante das crises.

Hoje, os bairros que ainda persistem na zona rural não podem mais manter sua constituição isolada (se é que um dia foram isolados). Existem também antigos sitiantes que foram trabalhar nas fábricas e agora voltam para a roça, seja para passar o fim de semana, seja para retomar os sítios da infância e residir permanentemente, reatando o contato com mestres do saber ou do fazer que se mantiveram a duras penas no campo durante os períodos mais intensos de industrialização.

Porém, contrariamente ao que previa Candido, verificamos que mesmo após - Vale do Paraíba haver passado por mudanças drásticas em sua composição populacional, as narrativas orais e outras práticas caipiras continuam também marginalmente, mas, agora, de outro modo a serem praticadas.

Por outro lado, outros indivíduos, tendo permanecido na cidade e, em função de uma migração mais drástica, cortado definitivamente as incursões à roça, têm que lidar diretamente com o preconceito institucional e civil em relação a sua origem, seus hábitos e seus gostos, que insistem em se afirmar diante da frieza das relações sociais na cidade e mesmo da crise de representação pela qual passa a sociedade no presente momento.

Não há confiança na representatividades política, nem religiosa, sendo que a mídia também oferece uma representação totalmente voltada para o espetáculo e para a massificação, que, de maneiras diferentes, atinge a todos, mesmo nas zonas rurais mais afastadas. Diante disso, o indivíduo é impelido a atuar em espaços distintos, atendendo às necessidades de sua memória e aproveitando-se dos benefícios da entrada no ritmo capitalista, o que gera as mais diversas configurações culturais que atuam de forma marginal. São significativos os dois grupos de Folia de Reis estudados por nossa pesquisa, bem como a grande diversidade de contadores de estórias espalhados pelas áreas urbana e rural. Em síntese, são estas as necessidades que agora se impõem para a consideração da cultura caipira.

Em nosso contexto, a valorização do passado tradicional como algo em constante reequilíbrio é fundamental como resistência cotidiana que age nas brechas dos processos econômicos de mudança, agressivos em relação às culturas que seguem o ritmo do sagrado popular, como os grupos caipiras.

Entretanto, em relação ao estudo de Candido, este quadro já significaria a 
morte da cultura, pois os indivíduos já não se organizariam mais na forma socialmente fechada do bairro rural, mas já estariam contaminados pelas expectativas do consumo capitalista, o que significaria o desapego das práticas consideradas rústicas. Entretanto, como podemos configurar o ressurgimento de grupos tradicionais e a continuidade geracional das práticas de narração oral em vista de novas configurações sociais que se apresentam mais fluídas?

A contradição é apenas superficial. A base do método de Candido se constituía, acima de tudo, na construção do conhecimento teórico dentro da pesquisa participante, ou seja, delineando as necessidades mais imediatas. Secundariamente, as particularidades históricas que pudessem denunciar a opressão mais pungente, também seriam enfatizadas, pois esse era o momento do livro.

Assim, levando em conta que Antonio Candido é cuidadosamente discreto em relação a suas fontes teóricas, o terceiro capítulo do livro deve ser lido em acordo com boa parcela dos trabalhos publicados nas décadas de 1950 e 1960, no Brasil.

Na antropologia, com o impacto dos 'estudos de comunidade', introduzidos
no Brasil por Emílio Willems e Donald Pierson, respectivamente, na USP e
na Escola Livre de Sociologia e política, a questão fundamental é entender
a natureza da mudança social. Na sociologia, a partir dos anos cinquenta,
as pesquisas se voltam para a explicação das grandes transformações que
ocorrem na sociedade brasileira naquele momento, relacionados à
modernização do país, em função da aceleração dos processos de
industrialização, urbanização, formação da sociedade de classes e
democratização política. (JACKSON, 2002, p. 59).

Duas questões são aparentemente colocadas na ordem do dia pelo autor: natureza da mudança social e condições de possibilidade das grandes transformações sociais ${ }^{6}$ que ocorriam, integrando, de certa forma, a análise da situação de crise da cultura caipira diante da expansão da economia capitalista.

Como foi citado acima, o delineamento da natureza da mudança se baseia no contraste da rusticidade histórica (termos mínimos), com as modificações impostas pela sociedade mais abrangente. Nesse sentido, o emprego de uma sociologia dos meios de subsistência, colocando as afinidades que estabelece com a natureza para sobreviver e a satisfação das necessidades como mola da cultura ${ }^{7}$, são ideias eficientes e desnudam a desigualdade sobre a qual se assenta a sociedade mais abrangente.

A perspectiva mais fechada e funcionalista talvez se explique por pelo fato de que o engajamento político tornava prioritário o delineamento dos mecanismos de 
exploração do homem do campo. Porém, em relação às configurações atuais, os compromissos emergenciais do autor rendem uma interpretação que acaba limitando sua proposta ${ }^{8}$ e retirando do caipira qualquer possibilidade liberdade de ação em relação ao sistema que the impõe o consumo e a destruição de sua cultura.

O preço desta limitação é a simplificação dos processos psíquicos que diferenciam os indivíduos. Podemos constatar isso verificando a base teórica com a qual Candido trabalha para poder definir os conceitos de mínimo vital e social:

\footnotetext{
Para definir o caráter psicológico do caipira, ele recorre a uma tipologia semelhante àquela formulada por Sérgio Buarque de Holanda em Raízes do Brasil, contrapondo trabalhador e aventureiro. O gosto pela aventura prevalece diante do trabalho metódico, o que implica sempre o provisório, o temo mínimo, suficiente para a sobrevivência. (JACKSON, p. 55).
}

Em função de uma psiquê simplificada baseada em tipos, e de um funcionalismo que o ata aos mínimos vitais, o caipira é vítima de uma frustração que o acompanha, mesmo quando a fome física está satisfeita: a fome psíquica ${ }^{9}$. Assim, talvez o maior obstáculo, para nosso trabalho, seja que, apesar de verificarmos práticas simbólica espontâneas na oralidade caipira, por meio dos relatos colhidos, temos o problema do tolhimento da liberdade do indivíduo como agente da simbolização, em função de aspectos socioculturais. Todas as suas decisões, de alguma forma, já seriam determinadas pela falta da alimentação.

\section{GUIMARÃES ROSA POR SUZI SPERBER: A VALORIZAÇÃO DA COMPLEXIDADE INDIVIDUAL E A LIBERDADE}

Em relação a outro contexto e corpus, mas deparando-se com um problema semelhante, Sperber, por sua vez, apreende a multiplicidade existencial com que Rosa apresenta o sertanejo, justamente por meio de pressupostos de Candido que não os de Os parceiros do Rio Bonito. A autora mostra, em Caos e Cosmos (1983) como, por meio das leituras espiritualizantes, de diferentes categorias, feitas por Guimarães Rosa, é possível considerar o sertão como potência de significados não redutíveis aos sistemas de opressão social. O sertanejo não é definido em função da cultura dita civilizada, mas apresentado como ser múltiplo e não cristalizável por tipologias.

Isso é possível, pois, quanto a Rosa, em texto de 1982, Candido reconhece a necessidade de uma outra chave de análise, distinta do que vinha sendo chamada 
de regionalismo no Brasil, até então gênero no qual Rosa tinha sido enquadrado por alguns teóricos. Sperber, no prefácio de Signo e sentimento, cita Candido:

Guimarães Rosa publicou em 1946 um livro de contos regionalistas,
Sagarana, com inflexão diferente graças à invenção rara do entrecho e à
construção inovadora da linguagem. Prosseguindo silenciosamente nesse
rumo, ele o aprofundou durante anos numa série de contos longos, o último
dos quais cresceu ao ponto de se tornar um romance: respectivamente
Corpo de baile (2 volumes) e Grande sertão: veredas, ambos publicados em
1956. [...] Muito mais que no caso de Clarice Lispector, esses livros foram
um acontecimento, porque tomavam por dentro uma tendência tão duvidosa
quanto inevitável, como o regionalismo, e procediam à sua exploração
exaustiva, quase implacável do mais discutível particular. [...] Guimarães
Rosa cumpriu uma etapa mais arrojada: tentar ao mesmo resultado sem
contornar o perigo, mas aceitando-o, entrando de armas e bagagens pelo
pitoresco regional mais completo e meticuloso, e assim conseguindo anulá-
lo como particularidade para transformá-lo em valor de todos. O mundo
rústico do sertão ainda existe no Brasil e ignorá-lo é um artifício. Por isso ele
se impõe à consciência do artista, como à do político e do revolucionário.
Rosa aceitou o desafio e fez dele matéria, não de regionalismo mas de
ficção pluridimensional, acima do seu ponto de partida contingente.
(CANDIDO, 1981).

É a partir desses pressupostos que Sperber constata a apreensão que Rosa faz das bases espirituais do povo, evidenciando um Brasil no qual o autor que rege é noção de mudança interior constante em que mesmo os significados mudam, em um movimento que remete à ascese espiritual e exige uma base psíquica complexa. (SPERBER, 1984, p. 2)

É importante salientar também que a base dos métodos de análise de narrativas adotados pela autora (principal fundamento de seu conceito de pulsão de ficção [SPERBER, 2009, p. 59]) é justamente o movimento que Candido atribui a Rosa, de anular o regionalismo como "particularidade para transformá-lo em valor de todos". A pulsão de ficção baseia-se na existência de universais atuantes na compreensão humana e que tornam possíveis o desenvolvimento psíquico de todos os seres humanos, independentemente de determinações... como a restrição alimentar $^{10}$. Assim a autora aponta para uma outra maneira de compreensão da oralidade:

\begin{abstract}
A formação de minha teoria partiu da produção do texto oral, do sujeito embrionário em formação e do seu potencial. Visava uma micro-luta pessoal, minha: a de comprovar que todos os seres humanos têm virtualmente um potencial para o conhecimento e para a produção semelhante, que basta ser estimulado para se desenvolver. (CANDIDO; SPERBER, 2011, p. 55).
\end{abstract}

Segundo a estudiosa, em Grande sertão: veredas, o indivíduo é visto como 
forma essencial da realidade (SPERBER, Caos e Cosmos, p. 120), em um posicionamento que aponta para o indivíduo como a instância mais aglutinante do processo de significação, em detrimento do grupo social ou da comunidade. Assim, somos inclinados a pensar em como esse indivíduo organiza essa realidade e a compreende.

Nota-se que a autora trilha um caminho até então inexplorado, analisando a complexidade verificada por Rosa no sertanejo e, em vez de enveredar pela busca de funções instintivas e sociais que impulsionariam o homem, valoriza justamente a liberdade de simbolização, comum a todos e um dos eixos temáticos de Grande sertão: veredas ${ }^{11}$. Ainda que não trate especificamente do caipira do interior de São Paulo, esta perspectiva nos abre novas possibilidades para a consideração de narrativas orais, pois há uma distância grande entre o indivíduo em Os Parceiros, e o indivíduo que Candido enxerga como matéria ficcional de Rosa em Grande Sertão.

O funcionalismo histórico econômico teria limitado profundamente a pesquisa de Sperber sobre a obra de Guimarães Rosa se a pesquisadora não relevasse uma relativização feita em relação à própria aplicabilidade do materialismo histórico para a exegese rosiana. A obra não poderia ser colocada dentro desses parâmetros sob risco de reducionismo. Em nosso caso, a questão passa um pouco por essa discussão, pois a necessidade da consideração puramente sociológica (em perspectiva puramente materialista-historicista) acaba por limitar a existência individual. Por outro lado, o funcionalismo dos termos mínimos tolhe a liberdade individual.

\section{A PULSÃO: O JOGO E A PALAVRA}

Em consideração ao exposto acima, optamos por transferir da comunidade de bairro, para o indivíduo e seu espaço imediato, da família, os pressupostos de coerência para a análise de narrativas. Consideramos que não basta catalogar os hábitos do indivíduo até compor um quadro ordenado: em cada indivíduo a cultura assume características diferentes.

A dificuldade de quantificação da cultura decorre da presença ineliminável do qualitativo, do individual. Apenas assim, os elementos objetivos e subjetivos acabam por se complementar e emergem na construção da efabulação.

Como um ponto de partida para a constituição do subjetivo, descreveremos 
brevemente a constituição de uma base psíquica. Segundo Freud, dentro das leis próprias que o sistema de expressão do sonho constitui, a palavra poética é elemento de figuralidade cujo processo de significação se forma entre a noção abstrata e a imagem sensorial. Este é o âmago do processo de simbolização e, se amplificado, da efabulação ${ }^{12}$. O princípio organizativo do trabalho com a palavra vem de pulsões básicas, de vida e de morte, que formam a pulsão de ficção presente em todos os seres humanos.

Esta pulsão é responsável pelo desenvolvimento psíquico, o que denota a função cognitiva da literatura "na medida em que leva a que se descubram sempre novas relações, outras formas de conhecimento e outra relação do eu e do outro, em diálogo." (CANDIDO; SPERBER, 2011, p. 28). O processo de cognição se dá, geralmente, por meio do jogo, e da repetição, cuja constância potencializa a ressignificação da experiência.

Em nossa pesquisa, praticamente todos os contadores revelavam um grau de valorização da palavra em seu poder de criar novas possibilidades. A palavra, seja no serão, seja na música, é motivo de socialização, de criação de novos significados, de fruição, de atenuação da dor, ou ainda de intensificação do sofrimento, se usada de forma repressiva ou como valor negativo.

Em um primeiro momento, objetivando descrever o trabalho com a palavra na oralidade caipira, ao perguntarmos sobre o processo de criação narrativa a um contador de histórias, obtivemos a seguinte definição:

Ô Daniel, a gente lembra bem do passado quando a gente deita e dorme. Quando acorda, acorda, começa a lembrar, a lembrar. Uma vez, o Daniel, eu levantei, eram três horas, fui no banheiro. Quando cheguei na mesa aqui, vi uma revista, com uma capa mulher bonita. Quando a mulher. Eu vi aquilo e fui pra cama. Aí eu comecei a cantar um pagode e foi longe, Daniel, e foi longe. Só me alembro do começo: A mulher quando é bonita, vai ser capa de revista. $O$ cão picado de cobra tem medo até de linguiça. $O$ meu cachorro só morre quando o papagaio apita. To alegre e to feliz, cantando por ser paulista. Eu comecei a cantar e pensar, pensar, pensar, pensar. Só que. Eu cantei uma porção de vezes o pagode. Mas esqueci de tudo o pagode. Não pode esquecer, não pode nem assinar meu nome. Tem que levantar e escrever na hora. (EMBOABA, 2013).

Talvez o aspecto mais evidente, na descrição do contador, seja a necessidade do jogo com as palavras. O contador descreve a forma espontânea com que o jogo se manifesta em seu cotidiano, em uma interação com a memória.

O psicólogo russo Vygotski realizou estudos fundamentais sobre o papel 
psicológico do jogo no desenvolvimento humano. Não seria difícil associar o jogo descrito acima ao constante desenvolvimento do trabalho expressivo no cotidiano individual. Johan Huizinga (1938), por sua vez, apresenta o jogo como um fenômeno fundamental da cultura, que se encontra, como atividade lúdica, presente na linguagem, no direito, na guerra, na ciência, na poesia, na filosofia e nas artes.

Assim, o jogo também assume como características o prazer da fruição, que lhe atribui um aspecto de gratuidade, não funcional; implica afetos, imaginação, sentidos e também intelecto, e é, nesse sentido, um fenômeno que envolve, principalmente, a ordem do sensível, sem, contudo, negligenciar aspectos inteligíveis.

Voltando à descrição feita por André, é evidente a preocupação do contador em apresentar o jogo com as palavras como atividade lúdica e de fruição, relacionada ao prazer e ao ritmo da memória. Não há uma causa específica para a energia que se Ihe apresenta em demanda de efabulação e, em contrapartida, esta não é função de um determinante específico, como a obsessão pela comida, pelo sexo ou coisa que o valha, mas um estado de sentimento e percepção em que podemos verificar pulsão, estímulos visual e jogo.

Em síntese, podemos perceber a energia que move a sintaxe do sonho à procura de uma experiência que mereça ser significada. Isso porque o estado descrito corresponde ao de vigília, em um estado limítrofe entre o acordar e o dormir. Assim, já podemos considerar que são vários os fatores que incidem na efabulação: exógenos e endógenos, o que torna impossível determinar a motivação exata do processo de criação.

No exemplo dado pelo contador, a livre associação com as palavras é patente, e, aparentemente, ainda não há necessidade de uma coerência que estabeleça firmemente a ligação entre os elementos. A criação, ali, por enquanto é descompromissada e lúdica, segue mais o ritmo dado pelas sugestões do inconsciente e da percepção que internaliza signos concretos: $A$ mulher quando é bonita, vai ser capa de revista. $O$ cão picado de cobra tem medo até de linguiça. $O$ meu cachorro só morre quando o papagaio apita. To alegre e to feliz, cantando por ser paulista.

Porém, já é possível notar a transferência de significados de elementos externos que passam a incorporar uma estrutura verbal, bem como o trabalho do imaginário e a decisão advinda de uma intenção. 
O jogo revela, pelo menos inicialmente, que o acontecimento externo repercutiu no sujeito, transformando-se em interno. É também revelador de que o real, elemento externo de um acontecimento, passou a um nível de figuração particular, pessoal (que estou chamando de imaginário), de construção de uma ação segunda, que está no lugar da primeira - real mediante o uso de símbolos também. (SPERBER, 2009, p. 87).

Efervescida por essa pulsão, no que Husserl designava como a camada préexpressiva do vivido ${ }^{13}$, a existência, enquanto não repartida e limitada pela "divisão do trabalho mental" apresenta-se na sua variadíssima concreção de aspectos, formas, sons, cores, no qual a livre associação de palavras, em si, gera prazer, mas também já começa a se organizar formalmente em projeto por meio de ritmo e de rima.

Podemos amplificar ainda mais esse jogo com a associação de eventos, o que cria a narrativa. Narrar expressa nossa maneira de viver no mundo e envolve um trabalho comunitário de construção de um mundo inteligível. Assim, a dinâmica do jogo dá forma às sucessões disformes e silenciosas dos acontecimentos e estabelece relações entre eles.

Nesse sentido, além da fruição, gratuita ou não, o jogo também comporta uma seriedade, que envolve o corpo. Logo após o relato acima, o mesmo contador continua sua explicação sobre a criação verbal, descrevendo o canto como um modo de suportar mesmo a dor do corpo:

É, mas a gente começa a lembrar muita coisa, muito passado, muita coisa.
Uma vez, eu passei na serra e vi dois homens: o Geraldo Barbosa e o Zé
mineiro. Daí eu comecei a falar, conversar com ele, daí ele falou - Mas você
não tem hora de andar. É com sol, é com chuva, é com frio. Daí o Zé
Mineiro falou - mas pode estar chovendo e o André passa cantando ainda.
Sofrendo e cantando. Falei - Seu Zé, a gente canta pra não chorar. Se
cantando é ruim, chorando é pior.

Lidar com a experiência dolorosa por meio do jogo é um processo complexo, mas muitas vezes necessário, no qual a efabulação possibilitada pela palavra, pela música, ou por quais meios as pulsões apontarem, toca também o sentido existencial. Sobre a seriedade no jogo, Huizinga diz:

[...] o jogo autêntico e espontâneo também pode ser profundamente sério. 0 jogador pode entregar-se de corpo e alma ao jogo, e a consciência de tratar-se 'apenas' de um jogo pode passar para segundo plano. A alegria que está indissoluvelmente ligada ao jogo pode transformar-se, não só em tensão, mas também em arrebatamento. A frivolidade e o êxtase são os dois polos que limitam o âmbito do jogo. (HUIZINGA, 2004, p. 24). 
Sem o jogo, a estruturação do projeto ficcional de ressignificação da experiência sofrida seria tão dolorosa quanto a experiência a ser ressignificada. Sperber descreve esse ato como, inicialmente, uma conversão do ativo em passivo para que a experiência possa ser transcendida. Só assim é possível a "reconversão do passivo em ativo por meio do jogo, i.e., por meio da criação de um recurso de palavras com usos e níveis de sentido diferentes" (SPERBER, 2009, p. 81). A dinâmica de ativo e passivo gera um movimento que abre uma sequência de elementos no tempo, cujo conjunto encadeado é mais que os fatos isolados, e permite que se possa, por meio da compreensão, superar, transformar, ou, ao menos, compreender a experiência .

No processo efabulativo, nos termos de Sperber (2009, p. 91-92), "o imaginário fabrica um constructo que existirá entre o sujeito e o mundo", aguçando os modos de percepção, abrindo os seus canais. A autora identifica três movimentos que apontam para a superação e geram conhecimento:

Um consiste em deixar-se penetrar pelo mundo (cor, imagem, som, ritmo,
espaço, linhas, alturas, dimensões, eventos, emoções), isto é, aproximar-se
do mundo; o outro consiste em, ao mesmo tempo, afastar-se dele, para
mais tarde agir sobre o mundo. O fruto da simbolização (mais
concretamente da efabulação) está entre o sujeito e o mundo. [...] O
terceiro movimento, de síntese do processo de percepção e de efabulação,
será o início de novo momento e movimento, que amplia, ou regride, que
abrange novos elementos no constructo, ou na forma dada que, na sua
característica ficcional, organiza, dando sentido ao conjunto de elementos
díspares. (SPERBER, 2009, p. 91-92).

Essa organização não quer dizer que, à medida que o projeto efabulativo se consolida, o prazer do jogo cesse e mesmo o inconsciente deixe de atuar. O projeto efabulativo segue uma intenção hermenêutica consciente, de vontade de significar, cuja força é proporcional à necessidade de controlar e dar sentido à experiência. A pulsão de ficção (SPERBER, 2009, p. 87) é a condição de possibilidade desse processo. Consiste no investimento simbólico que movimenta a elaboração ficcional, e é o que liberta o ser das amarras de qualquer determinação. Sua forma elementar efervesce nas pulsões de morte e de vida, que enformam as ações humanas:

Combinando o conceito de pulsão de ficção com o de pulsões freudiano, as formas procuradas pela pulsão de ficção poderia corresponder ao impulso para as superações, para a vida; ou a obediência e respeito às normas, tradições, preceitos da coletividade. Ou mesclas entre ambos os impulsos, podendo tender mais para o conhecimento dos preceitos e à adequação a eles, ou mais à busca de saídas, com hesitações, angústias, ambivalências. 
(CANDIDO; SPERBER, 2011, p. 55).

Em consideração a esta brevíssima análise, podemos constatar algo da complexidade da base psíquica envolvida na efabulação. Isso porque diversos fatores incidem na atividade simbólica e se relacionam profundamente com o aspecto cognitivo. Um indivíduo pode ter realmente uma obsessão pela comida assim como outro acaba por trabalhar quantos aspectos psíquicos a mente humana pode apresentar. A internalização de nexos sociais também pode transparecer no processo efabulatório na medida da permeabilidade do sujeito. A própria pulsão pode ainda exacerbar o prazer do jogo, misturando elementos na direção de mundos fantásticos, como no causo, em que o desafio à racionalidade estrutura a forma. Todos esses fatores se fazem presentes em maior ou menor grau. Entretanto, não podemos eleger apenas um aspecto qualitativo e colocá-lo como definidor da cultura.

Logo acima procuramos descrever a efabulação como uma forma de conhecer e produzir conhecimento, sendo, senão, a própria forma do conhecimento humano, pois este consiste na organização de fatos aleatórios em busca de um sentido. Isso nos abre caminho para relativizar (no sentido de por em relação) pressupostos que afirmam que o caipira sofreria de insuficiência simbólica devido à limitação pela comida. Entretanto, preconceitos são verificados não apenas em relação à capacidade criativa, mas também à maneira de pensar do homem do campo. Supostamente ineficiente, pois empírica.

Sendo assim, há que se salientar que a presença da leitura de Sérgio Buarque de Holanda em Os parceiros gera uma outra concepção cognitiva que nos é cara: a relação quase simbiótica entre o caipira e a natureza. Essa concepção, quando não esclarecida, acaba por reduzir as comunidades rurais a um negativo em relação a um pretenso paradigma civilizado.

Antonio Candido, seguindo os passos de Buarque e Freyre, acreditava que a compreensão de nossos grupos rústicos deve passar necessariamente pela relação quase direta entre homem e meio (JACKSON, 2002, p. 10). O problema é que a noção psicológica simplificada em tipos básicos, inicialmente elaborada por Holanda, também acaba entrando nesse domínio. Os dois tipos que comporiam o caipira: aventureiro e indígena, acabam desencadeando a separação entre aqueles que vivem "em função do meio" e os que se libertaram do empírico e se civilizaram, como quem se livra de uma marca de atraso. O pensamento embutido desta 
concepção sugere que as comunidades rurais e indígenas não são capazes de raciocínio lógico e abstrato, e são marcadas pelo empírico, ao passo que os indivíduos considerados "civilizados", já dominam a abstração.

Assim, em várias narrativas orais, pudemos realmente constar a predominância da orientação pelo empírico, em uma relação de proximidade que representa quase uma leitura da natureza. O próprio narrador cujas narrativas escolhemos para este trabalho, André Emboava, mais de uma vez relatava com precisão, em uma anamnese, como conseguia reconhecer e domar um animal simplesmente avaliando seus sinais mais contingenciais, como o modo de andar, o olhar e mesmo o jeito de se alimentar do animal. Da mesma forma, tal relação com a natureza pode ser verificada na descrição da observação dos astros para a revisão do tempo; pela interpretação de sinais no mato em busca da caça, etc.

Entretanto, talvez seja significativo mencionar que esse mesmo padrão de interpretação de sinais externos pode ser verificado em narrativas de ressignificação da experiência pessoal, bem como definindo relações familiares.

Em outra narrativa de André, em que o narrador novamente descreve a origem de sua habilidade para efabular, pode-se verificar uma divisão, em partes iguais, atribuindo ao pai e à mãe o possível aprendizado da arte da narração: Olha, o Daniel, eu puxei os dois lados. E o narrador vai delimitando dois campos de experiência distintos. A descrição do pai, relacionado à proibição e à pouca comunicação verbal, é feita por meio da descrição de sinais físicos: Por que o meu pai tinha o nariz igual ao meu. Para a mãe outro modo de avaliação é empregado: Mas eu sou ruim igual à minha mãe; apontando para a interioridade.

É surpreendente como o narrador vai estruturando a narrativa por meio destes dois paradigmas, que se cruzam, mas permanecem sempre muito bem delineados e, ao final, desembocam dramaticamente na explicação da origem da efabulação, em uma verdadeira ressignificação da experiência traumática. $O$ pai se ligava ao modelo de interpretação usado no mundo do trabalho e na lida com a natureza, ao passo que não havia comunicação afetiva. Assim, o único modo de descrever a identidade paterna é por meio de sinais externos, sendo que o mesmo critério acaba abrangendo a irmã. A mesma narrativa apresenta um jogo entre sinais externos/silêncio e interioridade/efabulação que se resolve em música, mas cuja interpretação geral escapa aos objetivos deste artigo. Entretanto, segue a narrativa. 
Daniel: E essa coisa, o senhor gosta muito de conversar; o senhor gosta muito de contar história. Esse lado comunicativo do senhor, o senhor acha que vem dos dois também?

André: Pois é, ô Daniel. Por que o meu pai nunca falou comigo.

André: única coisa que o meu pai falou, ele falou não pra mim, falou pra outro e eu escutei: "eu não registro a Cecília por que a Cecília não é minha filha." E nós chamava "o papai", "papai", "papai". Ela não aprendeu a falar "papai". O meu pai. E a Cecília é diferente. A Cecília é diferente. Baixinha. Gorda demais, tem a tem até um congote de duro. Você conhece a Cecília? Daniel: A mãe do senhor contava história pro senhor? Eu lembro que o senhor me falou.

André: Contava muita história, brigava. Dava pancada. Ela surrava. Eu fiz ultrassom esses dias, o médico falou, no começo do ano. Eu tenho um defeito no rim. Uma doença no rim.

Por que eu trabalhei, ô Daniel. Mas toda a vida eu senti a dor no rim, nas costas, deste lado aqui.

Daniel: Esse problema no rim o senhor acha que é por causa de quê?

André: Ah, é resultado da surra que eu levei, por que a surra que eu levei eu lembrei toda a vida. Eu tinha dor nas costas, dor eu sinto até hoje. Só que a gente acostuma.

Daniel: E o senhor lembra porque o senhor apanhou? O senhor lembra o motivo...?

André: O motivo, Daniel, eu vou falar pra você. Um dia eu estava brincando aqui. A minha mãe falou: "Vá na venda e traga um quilo de farinha pra mim". A vendinha é onde era do João Mamede, pra cá da estrada do Afonso. Eu fui na venda e tudo. E larguei a farinha e fui brincar de novo. Tinha muita criançada brincando aqui. Quando eu vi, ela começou a surrar eu. "Mais por que a senhora te surrando eu?" "Por que não trouxe a farinha pra mim, Você não foi À venda." "Eu fui, tá aqui". Então eu vou dar umas relhadas para esquentar o frio."

Daniel:O pai do senhor era bravo também, ou não?

André:Não. Não falava, só conversava com os outros.

Uma vez eu tava aqui, ô Daniel. Com uma gaitinha de boca chegou outro par e pegou duas colheres e começamos a fazer batucada. André: Batia as colher e fazia batucada.

Olha, e foi, foi, foi. O meu pai chegou, e era um dia de sábado de tarde, tava escurecendo. Meu pai falou aquilo; toda a vez que eu vai o papai falar: "vagabundo, bobo! Dois bobos se encontraram, começou a fazer batucada com a gaitinha ali."

(O contador sai rapidamente da cozinha e vai até seu quarto. Alguns segundos após um grito de surpresa, ele volta com uma gaita de boca.)

André: Ta aqui a gaitinha da estimação! Ás vezes eu começo a tocar gaita e começo a chorar. Lembrar o passado. (EMBOABA, 2013).

Os dois modelos epistemológicos presentes na narrativa nos permite delinear duas posições em relação à realidade. Por um lado, o campo das ideias abstratas, no sentido da possibilidade de se abstrair o que é concreto, paradigma aperfeiçoado na vivência com a mãe e com o qual pode trabalhar elementos de seu universo interior, com os quais e desenvolve a valorização da palavra como ponte para a subjetividade. Por outro lado, o reconhecimento de sinais externos, empregado quando todos os elementos apresentados para a identificação são externos e dependem da observação, e que vira critério diante da falta da palavra que permita o contato socializador. 
Assim, as palavras concretas (nariz, pescoço, "congote") como sinais de descrição o pai e da irmã têm por destino vincular estritamente a fala a um preciso campo de experiência: o empírico. De acordo com Ginzburg,

durante milênios o homem foi caçador. Durante inúmeras perseguições, ele aprendeu a reconstituir as formas e movimentos das presas invisíveis pelas pegadas na lama, ramos quebrados, bolotas de esterco, tufos de pelos, plumas emaranhadas, odores estagnados. Aprendeu a farejar, registrar, interpretar e classificar pistas infinitesimais como fios de barba. Aprendeu a fazer operações mentais complexas com rapidez fulminante, no interior de um denso bosque ou numa clareira de ciladas. (GINZBURG, 1990, p. 151).

O autor descreve o conhecimento empírico como um patrimônio cognoscitivo que teria sido transmitido por gerações e gerações de caçadores. O que caracteriza esse saber é a capacidade de, a partir de dados aparentemente negligenciáveis, remontar a uma realidade complexa não experimentável diretamente. Os dados são sempre dispostos pelo observador de modo tal a dar lugar a uma sequência narrativa cuja formulação mais simples poderia ser "alguém passou por lá". Assim, talvez não seja infundado afirmar que André infere relações inter-humanas complexas por meio do emprego deste conhecimento.

De acordo com Ginzburg, talvez a própria ideia de narração tenha nascido pela primeira vez numa sociedade de caçadores, a partir da experiência da decifração das pistas. O caçador teria sido o primeiro a 'narrar uma história' porque era o único capaz de ler, mas pistas mudas (se não imperceptíveis) deixadas pela presa, uma série coerente de eventos. (GINZBURG, 1990, p. 152).

Entretanto, a relação dos sinais com contextos específicos e com o empírico teria sido escondida pela invenção da escrita, que, progressivamente deu prioridade apenas aos elementos reprodutíveis do texto ${ }^{14}$. "Tudo isso nos parece óbvio, hoje, mas não o é em termos absolutos. Basta pensar na função decisiva de entonação nas literaturas orais, ou da caligrafia na poesia chinesa, para perceber que a noção de texto que acabamos de invocar está ligada a uma escolha cultural de alcance incalculável." (GINZBURG, 1990, p. 157).

As formas de conhecimento indiciário, mais ligadas à prática cotidiana, ficaram simplesmente de fora como paradigmas elegíveis. Isso porque a capacidade de reconhecer um cavalo defeituoso pelos jarretes, vinda de um temporal pela repentina mudança do vento, certamente não se aprende nas escolas, o que impedia seu controle. 


\begin{abstract}
Em todo o caso, essas formas de saber eram mais ricas do que qualquer codificação escrita; não eram aprendidas nos livros, mas a viva voz, pelos gesto, pelos olhares; fundavam-se sobre sutilezas certamente não formalizáves, frequentemente nem sequer traduzíveis em nível verbal; constituíam o patrimônio, em parte unitário, em parte diversificado, de homens e mulheres pertencentes a todas as classe sociais. Um sutil parentesco as unia: todas nasciam da experiência, da concretude da experiência. (GINZBURG, 1990, p. 167).
\end{abstract}

Assim, as instituições ligadas a algum poder e pautadas pela escrita, após a invenção da imprensa, oficializaram a desvalorização do conhecimento indiciário, pois este se encontra muito distante de qualquer forma de conhecimento que pode vir a ser privilégio de poucos eleitos, afinal, é um conhecimento dominado pelo povo. Mas foi a este eficiente paradigma epistemológico que o Estado recorreu, no século XIX, na Inglaterra colonialista, quando visava à identificação mais eficiente já conseguida: a identificação digital. Assim, podiam controlar os indianos, que, aos seus olhos, eram todos iguais.

Entretanto, este conhecimento não foi apenas empregado na identificação. Apesar de não ser reconhecido, grande parte do conhecimento ocidental advém da oralidade e da concretude da experiência. Talvez, na literatura isto se torne mais evidente. Podemos elencar, por exemplo, o episódio do reconhecimento da cicatriz de Ulisses, na llíada; ou, mesmo a Bíblia, onde o conhecimento (cognitio) do nascimento de Cristo é feito por meio de sinais astrológicos. Segundo Ginzburg (1990, p. 178), Em busca do tempo perdido é construído segundo um rigoroso paradigma indiciário.

Notavelmente, No Caminho de Swann, que se concentra no período de formação do protagonista do romance supracitado, é marcado pelo amor intenso pela mãe e a pouca simpatia pelo pai, sendo que a identidade do pai é construída por meio de indícios físicos: um barômetro; e a da mãe pela intensa interioridade ${ }^{15}$. Ambos os campos epistemológicos são paradigmáticos para o desenvolvimento cognitivo do protagonista, delineando, inclusive duas visões de mundo que se atraem e ao mesmo tempo se chocam, de duas culturas diferentes: a da emergente Terceira República e a do Segundo Império, na França. Pode-se notar que a relação epistemológica feita pelo narrador proustiano é exatamente a mesma relação construída pela narrativa de André.

No entanto, não verificamos a necessidade de usar a literatura escrita para validar a oralidade. Pelo contrário, queremos mostrar que o conhecimento empírico 
não está somente presente na oralidade e que a abstração não se relaciona apenas à escrita.

A análise de narrativas orais tem mostrado que a forma de pensar que liga 0 homem com a natureza, entre os caipiras, em que a oralidade predomina, é a mesma que podemos encontrar na literatura em sua relação com o mundo. Infelizmente, uma das barreiras que desestimula e constrange aqueles que advém de culturas de predomínio oral, é a desvalorização de seu conhecimento em relação ao conhecimento tido como padrão.

Uma variante frequente nos discursos sobre a oralidade é a falta de estímulos determinada pela falta de alimentação como causa da limitação cognitiva. O indivíduo não teria as mesmas condições de acesso ao estudo sistematizado, e os estímulos de sua cultura seriam limitados. Nesse processo, os indivíduos não acabam por ser marcados e determinados pelo estigma da "falta de estímulos". O que, então, pode ser considerado estímulo? Ao que parece, o que se está considerando como estímulo talvez seja apenas o conhecimento tido como padrão, mas não a condensação simbólica da cultura de onde vem o indivíduo. Se a narração oral produz conhecimento, esse conhecimento não é valorizado.

Não objetivamos desvalorizar o estudo escolar, institucionalmente formalizado. Entretanto, desde o período colonial, em nosso país, o conhecimento sistematizado, controlado por aqueles que detêm o poder faz com que sua visão de mundo seja imposta às classes subalternas, marcadas pelo analfabetismo.

Diante disso, acreditamos que não há insuficiência simbólica na efabulação, e o problema não é a cultura. Todo indivíduo aprende a observar o meio em que vive e a se relacionar com ele. A cultura oferece modelos e estímulos. Na sociedade mais abrangente, um médico aprende a interpretar sinais externos e faz disso sua profissão. Se há algum problema cognitivo relacionado ao caipira, certamente não se relaciona à comida, mas ao constrangimento.

O homem do campo é constrangido a esconder e desvalorizar suas origens. Não é difícil encontrar indivíduos aparentemente obrigados a "esquecer" suas histórias quando são evangelizados por igrejas pentencostais. Geralmente o esquecimento é apenas aparente, pois as narrativas costumam surgir quando menos se espera. Em relação às escolas, o problema passa pela construção da identidade da criança. Isso porque a desvalorização do contexto social, da cultura e da forma de pensar de onde vem a criança, bem como a desvalorização do próprio 
indivíduo, são grandes fatores, ou de evasão escolar, ou, por outro lado, de negação constante da cultura de origem.

Ainda assim, não é por acaso que muitos indivíduos entrevistados por nossa pesquisa relatam que seu momento de liberdade é quando podem narrar. A efabulação é uma resistência à desvalorização por não poder ser determinada: ocorre nas brechas do sistema, longe de escolas, igrejas, fábricas.

\section{NOTAS}

${ }^{1}$ Mestrando em Teoria e História Literária pela Universidade Estadual de Campinas-SP - UNICAMP e bolsista de pesquisa pela FAPESP. Email: borgesdaniel26@yahoo.com.br.

${ }^{2}$ Este trabalho é parte da pesquisa de mestrado "Causos, trilhas que se refazem".

${ }^{3}$ Ver GOUVÊA, Luzimar Goulart. Monteiro Lobato e Mazzaropi e o imaginário caipira. Taubaté: Casa Cultura, 2013.

4 "Embora não faça referência direta a Weber ou Marx, Antonio Candido mostra que a transformação da sociedade caipira está submetida à racionalização crescente descrita por Weber e à alienação provocada pela mercadoria no capitalismo, conforme Marx." (JACKSON, 2002, p. 60).

\footnotetext{
${ }^{5}$ Nosso paradigma representativo é o município de Caçapava - SP, de 100.000 habitantes, localizado
} entre São José dos Campos e Taubaté.

${ }^{6}$ Pesquisar dados destas grandes transformações: estatísticas, documentos, estudos geopolíticos. Falar da expansão da economia capitalista nas décadas de 1960 e 1970.

${ }^{7}$ Em um encontro da Teoria da história de Marx e o funcionalismo de Malinovski, segundo Jackson (2002, p. 53)

8 (JACKSON, 2002, p.62).

9 "Pouco frequentes no prato, as misturas não saem da cabeça do caipira" (JACKSON, 2002, p. 58, 2002). COLOCAR A CITAÇÃO DE CANDIDO.

10 Segundo a autora, é mais fácil limitar o ser humano por constrangimento do que por restrições neurológicas como a falta de alimentação. O preconceito com os desfavorecidos economicamente acaba por marcá-los [...] "pelo selo do limite. Dentre os estigmas contamos com os provenientes da área médica. Haveria distúrbios irreversíveis de neurônios, decorrentes de falta de alimentação. Até a grande imprensa já divulgou casos em que a aparente irreversibilidade foi tornada reversível, recuperando-se completamente a criança em estágio desesperador de desnutrição." (SPERBER, 2009, p.56).

11 (Caos e Cosmos, p.88).

12 (CANDIDO; SPERBER, 2011, p. 73).

${ }^{13}$ (Husserl apud BOSI, 2000, p. 37).

14 "Inicialmente, foram considerados não pertinentes ao texto os elementos ligados à oralidade e à gestualidade; depois, também os elementos ligados ao caráter físico da escrita. O resultado dessa dupla operação foi a progressiva desmantelação do texto, continuamente depurado de todas as referências sensíveis: mesmo que seja necessária uma relação sensível para que o texto sobreviva, o texto não se identifica com seu suporte." (GINZBURG, 1990, p. 157). 
15 "Meu pai dava de ombros e examinava o barômetro, pois gostava de meteorologia, enquanto minha mãe, evitando fazer barulhos para não perturbá-lo, olhava-o com respeito carinhoso, mas não fixamente para não dar a entender que buscava devassar o mistério da sua superioridade." PROUST, Marcel. No caminho de Swann. Trad, Mario Quintana. Porto Alegre: Globo, 1948. p. 10.

\title{
COGNITION AND CULTURE CAIPIRA ORAL TRADITION: NARRATION AND EMPIRICAL EPISTEMOLOGY
}

\begin{abstract}
This paper aims to build a perspective of analysis for oral narratives considering cognitive aspects related to the act of storytelling. In this sense, it is necessary to outline the psychological bases involved in working with the word done by individuals of caipira culture of the city of Cacapava-SP. Therefore, it is proposed, as a starting point, the relativization of some assumptions for the Os parceiros do Rio bonito, from Antonio Candido, in order to take the specific symbolic of orality caipira in resistance and update in relation to economic changes that reach the Paraíba Valley. In this context, the literary analysis allows identifying the formal mediations that takes the word to express the individual experience and the individual's relationship with their sociocultural context.
\end{abstract}

Keywords: Literary theory. Orality. Caipira culture. Cognition. Epistemology.

\section{REFERÊNCIAS}

BOSI, Alfredo. O ser e o tempo da poesia. 6. ed. São Paulo: Companhia das Letras, 2000.

CANDIDO, Antonio. Os parceiros do Rio Bonito: estudos sobre o caipira paulista e a transformação dos seus meios de vida. 11. ed. São Paulo: Duas Cidades, 2010.

. Os brasileiros e a literatura latino-americana. Novos Estudos Cebrap, [s.I.], v. 1, n. 1, p. 58-68, dez. 1981.

CANDIDO; SPERBER. Teoria literária e hermenêutica ricoeuriana: um diálogo possível. Dourados, MS: UFGD, 2011. 
GINZBURG, Carlo. Mitos, emblemas e sinais: morfologia e história. Trad. Federico Carotti. São Paulo: Companhia das letras, 1990.

GOUVÊA, Luzimar Goulart. O homem caipira nas obras de Lobato e Mazzaropi: a construção de um imaginário. 2001. Dissertação (Instituto de Estudos da Linguagem)- Universidade Estadual de Campinas, Campinas, 2001.

HUIZINGA, Johan. (1938) Homo Ludens. 5. ed. São Paulo: Perspectiva, 2004.

JACKSON, Luis Carlos. A tradição esquecida: os parceiros do Rio Bonito e a sociologia de Antonio Candido. São Paulo: FAPESP; Belo Horizonte:UFMG, 2002.

SPERBER, Suzi Frankl. Caos e cosmos: leituras de Guimarães Rosa. São Paulo: Duas Cidades/Secretaria da Cultura, Ciência e Tecnologia do Estado de São Paulo, 1976.

. Guimarães Rosa, signo e sentimento. São Paulo: Ática, 1984.

Fiç̧ão e razão: uma retomada das formas simples. São Paulo: Aderaldo \& Rothschild; FAPESP, 2009.

THOMPSON, Paul. A voz do passado. São Paulo: Paz e Terra, 2002.

\section{Entrevista}

EMBOABA, André. Entrevista concedida a Daniel Batista Lima Borges. Caçapava SP, 28 set. 2013. 20 h. Áudio - WAVE. 